\title{
Article
}

\section{HFE Genotype, Ferritin Levels and Transferrin Saturation in Patients with Suspected Hereditary Hemochromatosis}

\author{
Miriam Sandnes ${ }^{1}$, Marta Vorland ${ }^{2}$, Rune J. Ulvik ${ }^{1}$ (D) and Håkon Reikvam 1,3,*(D) \\ 1 Department of Clinical Science, University of Bergen, N-5021 Bergen, Norway; \\ miriam.sandnes@uib.no (M.S.); rune.ulvik@uib.no (R.J.U.) \\ 2 Department of Cancer Genomics, Haukeland University Hospital, N-5021 Bergen, Norway; \\ marta.vorland@helse-bergen.no \\ 3 Department of Medicine, Haukeland University Hospital, N-5021 Bergen, Norway \\ * Correspondence: hakon.reikvam@uib.no; Tel.: +47-55-97-50-00
}

Citation: Sandnes, M.; Vorland, M.;

Ulvik, R.J.; Reikvam, H. HFE

Genotype, Ferritin Levels and

Transferrin Saturation in Patients

with Suspected Hereditary

Hemochromatosis. Genes 2021, 12,

1162. https://doi.org/10.3390/

genes12081162

Academic Editor: Paweł Lipiński

Received: 17 June 2021

Accepted: 28 July 2021

Published: 28 July 2021

Publisher's Note: MDPI stays neutral with regard to jurisdictional claims in published maps and institutional affiliations.

Copyright: (C) 2021 by the authors. Licensee MDPI, Basel, Switzerland. This article is an open access article distributed under the terms and conditions of the Creative Commons Attribution (CC BY) license (https:// creativecommons.org/licenses/by/ $4.0 /)$.

\begin{abstract}
HFE hemochromatosis is characterized by increased iron absorption and iron overload due to variants of the iron-regulating HFE gene. Overt disease is mainly associated with homozygosity for the $\mathrm{C} 282 \mathrm{Y}$ variant, although the $\mathrm{H} 63 \mathrm{D}$ variant in compound heterozygosity with $\mathrm{C} 282 \mathrm{Y}$ (C282Y/H63D) contributes to disease manifestation. In this observational study, we describe the association between biochemical findings, age, gender and HFE genotype in patients referred from general practice to a tertiary care referral center for diagnostic workup based on suspected hemochromatosis due to persistent hyperferritinemia and HFE variants. C282Y and H63D homozygosity were, respectively, the most and least prevalent genotypes and we found a considerable variation in transferrin saturation and ferritin levels independent of HFE genotype, which may indeed represent a diagnostic challenge in general practice. While our results confirm C282Y homozygosity as the major cause of iron accumulation, non-C282Y homozygotes also displayed mild to moderate hyperferritinemia with median ferritin levels at 500-700 $\mu \mathrm{g} / \mathrm{L}$, well above the reference cut-off. Such findings have traditionally been ignored in the clinic, and initiation of iron depletion has largely been restricted to $\mathrm{C} 282 \mathrm{Y}$ homozygotes. Nevertheless, superfluous iron can aggravate pathogenesis in combination with other diseases and risk factors, such as inflammation, cancer and hepatopathy, and this possibility should not be neglected by clinicians.
\end{abstract}

Keywords: iron; hemochromatosis; ferritin; transferrin saturation

\section{Introduction}

HFE hemochromatosis is an autosomal recessive disorder caused by variants of the iron-regulating HFE gene [1]. The phenotypic hallmark involves increased iron absorption, and it represents the most common monogenic disorder in individuals of northern European descent with a prevalence of approximately 1 in 150 to 350.

Of the two most prevalent variants involved in HFE hemochromatosis, C282Y and H63D, C282Y homozygosity is the principal defect ultimately generating a sizable parenchymal iron overload associated with increased risk of liver cirrhosis. Accordingly, 60-100\% of clinically diagnosed subjects are C282Y homozygotes, although other genotypes may sporadically generate a serious iron overload despite them being considered as low risk [2-4]. As a result of incomplete penetrance, there is a great variation in the associated clinical and biochemical phenotypes. Iron-rich food or iron supplements may influence phenotypic penetrance as well, and due to iron loss through pregnancy and menstruation, definite disease manifestation is significantly lower in women than in men [5-7].

While reported prevalence of iron-related disease in untreated C282Y homozygotes is generally regarded as low [8], phenotypic penetrance through biochemical perturbations of iron indices is high, with approximately $50 \%$ of women and $80 \%$ of men developing hyperferritinemia [9]. A progressive increase in ferritin (hyperferritinemia) as a sign of 
growing iron storages, and an elevated transferrin saturation (Tsat) as a marker of increased iron absorption are the earliest phenotypic abnormalities in HFE hemochromatosis [10].

In our region, inhabited by about half a million people, ferritin is the third most requested analysis from primary health care, making up about $80 \%$ of all ferritin analyses performed at the laboratory. As a consequence of this screening practice, persistent mild to moderate hyperferritinemia is sporadically detected in patients without clear evidence of disease, but with a hidden genetic risk for developing hemochromatosis. Ferritin is, however, recognized as an acute phase reactant which rises upon numerous conditions unrelated to iron overload. Hyperferritinemia is thus a highly unspecific finding, and the vast majority of patients presenting with elevated ferritin levels do not have hemochromatosis [11].

When reactive hyperferritinemia associated with underlying diseases as well as conditions which may mask hyperferritinemia (e.g., occult bowel bleeding and blood donations) have been thoroughly considered and ruled out, the finding of a coincidental increase in Tsat supports the likelihood of hyperferritinemia being related to an iron overload [5,12-14]. When suspicion of iron overload is maintained, patients are often referred to an outpatient hospital clinic or a specialist, for further assessment, follow up and referral for iron depletion through phlebotomy when indicated.

To improve our knowledge of the HFE genotype-phenotype, we examined biochemical profiles associated with various HFE genotypes in patients referred to our clinic.

\section{Materials and Methods}

\subsection{Patients}

The Regional Ethics Committee (REK Vest) classified the study as quality assurance; thus, we did not need ethical assessment and informed consent. The hospital data protection officer approved the study. For biochemical characterization in relation to the HFE variants, we retrospectively reviewed the hospital records of 409 patients who during 2013-2019 were referred from general practice to the outpatient clinic. These patients were, on the basis of clinical assessment, biochemical findings, HFE genotype and suspected iron overload, subsequently referred to phlebotomy. The study population encompassed 316 men $(77.3 \%)$ and 93 women $(22.7 \%)$ in total.

\subsection{Methods}

Blood samples were analyzed at the hospital's central laboratory by automatic routine methods validated to meet the highest technical quality demands. HFE genotyping was performed at the central laboratory for clinical genetics. Age at referral and laboratory findings from the diagnostic workup were obtained, including the following full blood parameters: hemoglobin $(\mathrm{Hb})$ and white blood cell count $(\mathrm{WBC})$, and the following serum parameters: ferritin, Tsat, C-reactive protein (CRP), alanine transaminase (ALAT) and gamma-glutamyl transferase (GGT). Viral hepatitis was ruled out in all patients through serology.

Based on medical history and laboratory tests, we were able to rule out recent blood donation, pathological bleeding (that might mask hyperferritinemia caused by iron overload), ongoing use of medication such as iron supplements and proton pump inhibitors, significant acute phase reactions (non-specific or due to known acute and chronic disease), toxic, cholestatic or inflammatory liver disease, diabetes mellitus type 2, metabolic syndrome, inflammation, infection, being significantly overweight and superfluous use of alcohol.

Statistical analyses were performed using the GraphPad Prism 9 software (version 9.1.0, San Diego, CA, USA). Groups were compared using two-tailed Mann-Whitney $U$-test. Spearman's rank correlation coefficient $(r)$ was used as a measure of association. Significant $p$-values are indicated in figures with asterisks: $\left({ }^{*}\right),\left({ }^{* *}\right)$ and $\left({ }^{* * *}\right)$, for $\leq 0.05, \leq 0.01$ and $\leq 0.001$, respectively. 


\section{Results}

\subsection{Demographic Data and Ferritin Levels at Referral}

Median age in men and women was 47.5 and 57.8 years $(p \leq 0.001)$, respectively (Table 1). On the group level, men were younger than women, with, respectively, $58 \%$ and $29 \%$ being $<50$ years of age (Table 2 ). In subgroups covering decades from the age of 30 and onwards, there was a steady, close to linear rise in ferritin with the highest to lowest median across age groups showing a difference of $271 \mu \mathrm{g} / \mathrm{L}$ in men and $276 \mu \mathrm{g} / \mathrm{L}$ in women.

Table 1. Descriptive statistics for patients included in the study.

\begin{tabular}{|c|c|c|c|c|c|c|}
\hline & Ref. Range ${ }^{\dagger}$ & & Observations & Median & Range & $p$-Value \\
\hline \multirow{2}{*}{ Age (years) } & \multirow{2}{*}{$\mathrm{N} / \mathrm{A}$} & Men & 316 & 47.5 & $16.3-85.2$ & \multirow{2}{*}{$\leq 0.001$} \\
\hline & & Women & 93 & 57.8 & $25.1-79.7$ & \\
\hline \multirow{2}{*}{$\mathrm{Hb}(\mathrm{g} / \mathrm{dL})$} & $13.4-17.0$ & Men & 341 & 16.0 & $13.6-25.7$ & \multirow{2}{*}{$\leq 0.001$} \\
\hline & $11.7-15.3$ & Women & 97 & 14.4 & $12.7-16.9$ & \\
\hline \multirow{2}{*}{$\operatorname{WBC}\left(10^{9} / \mathrm{L}\right)$} & \multirow{2}{*}{$3.5-11.0$} & Men & 240 & 6.2 & $3.6-12.1$ & \multirow{2}{*}{0.876} \\
\hline & & Women & 73 & 6.3 & $3.4-10.5$ & \\
\hline \multirow{2}{*}{$\mathrm{CRP}(\mathrm{mg} / \mathrm{L})$} & \multirow{2}{*}{$<5$} & Men & 306 & 1.0 & $0.1-19$ & \multirow{2}{*}{$\leq 0.001$} \\
\hline & & Women & 91 & 2.0 & $0.3-15$ & \\
\hline \multirow{2}{*}{ Tsat $(\%)$} & $15-45$ & Men & 316 & 44.1 & $11.9-93.0$ & \multirow{2}{*}{0.119} \\
\hline & $10-40$ & Women & 93 & 46.7 & $24.0-89.0$ & \\
\hline \multirow{2}{*}{$\begin{array}{c}\text { Ferritin } \\
(\mu \mathrm{g} / \mathrm{L})\end{array}$} & $34-300$ & Men & 316 & 712 & $310-2536$ & \multirow{2}{*}{$\leq 0.001$} \\
\hline & $18-240$ & Women & 93 & 631 & $234-4645$ & \\
\hline \multirow{2}{*}{$\operatorname{ALAT}(\mathrm{U} / \mathrm{L})$} & $10-70$ & Men & 310 & 39.0 & $11-243$ & \multirow{2}{*}{$\leq 0.001$} \\
\hline & $10-45$ & Women & 93 & 29.0 & $11-126$ & \\
\hline \multirow{2}{*}{ GGT (U/L) } & $10-80\left(15-115^{¥}\right)$ & Men & 307 & 34.0 & $9-346$ & \multirow{2}{*}{$\leq 0.001$} \\
\hline & $10-45\left(10-75^{¥}\right)$ & Women & 93 & 27.0 & $12-403$ & \\
\hline
\end{tabular}

$\mathrm{Hb}$, hemoglobin; $\mathrm{WBC}$, leukocyte particle concentration; CRP, C-reactive protein; Tsat, transferrin saturation ALAT, alanine aminotransferase; GGT, gamma-glutamyl transferase. ${ }^{\dagger}$ at Haukeland University Hospital. ${ }^{¥}$ men and women $\geq 40$ years of age.

Table 2. Ferritin levels at age split in decades.

\begin{tabular}{ccccccccc}
\hline Age (Years) & \multicolumn{2}{c}{ Men } & \multicolumn{2}{c}{ Ferritin $(\mu \mathrm{g} / \mathrm{L})$} & \multicolumn{2}{c}{ Women } & \multicolumn{2}{c}{ Ferritin $(\mu \mathrm{g} / \mathrm{L})$} \\
& $\boldsymbol{n}$ & $\%$ & Median & Range & $\boldsymbol{n}$ & $\%$ & Median & Range \\
\hline$<30$ & 40 & 12.6 & 582 & $310-2078$ & 5 & 5.4 & 644 & $234-764$ \\
$30-39$ & 60 & 19.0 & 645 & $355-1637$ & 4 & 4.3 & 425 & $330-648$ \\
$40-49$ & 84 & 26.6 & 700 & $349-1734$ & 18 & 19.4 & 485 & $328-4645$ \\
$50-59$ & 59 & 18.7 & 818 & $418-2000$ & 22 & 23.6 & 633 & $346-1696$ \\
$60-69$ & 58 & 18.4 & 723 & $375-2536$ & 28 & 30.1 & 650 & $386-1841$ \\
$>70$ & 15 & 4.7 & 853 & $446-1381$ & 16 & 17.2 & 701 & $359-1153$ \\
Total & 316 & 100 & 712 & $310-2536$ & 93 & 100 & 631 & $234-4645$ \\
\hline
\end{tabular}

\subsection{Distribution of HFE Genotypes}

The distribution of HFE genotypes in our study population is depicted in Figure 1. A total of 139 subjects were homozygous for the C282Y variant (95 men, 44 women) and 88 were compound heterozygous for the $\mathrm{C} 282 \mathrm{Y}$ and H63D variants (67 men, 21 women). These two genotypes accounted for $55.5 \%$ of the whole study population, corresponding to $51.3 \%$ and $69.9 \%$ of men and women, respectively. In descending order, the rest was made up of $85 \mathrm{H} 63 \mathrm{D}$ heterozygotes (69 men, 16 women), 71 C282Y heterozygotes (64 men, 7 women) and 26 H63D homozygotes ( 21 men, 5 women). Accordingly, in both genders, C282Y homozygosity was the most prevalent genotype, while H63D homozygosity was the least prevalent genotype in both genders. 


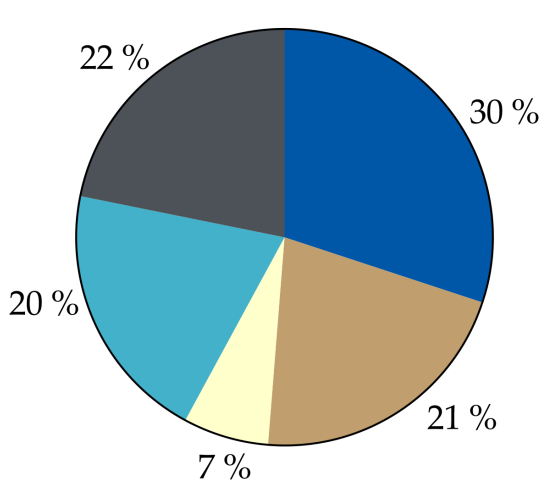

(a)

Total $=316$

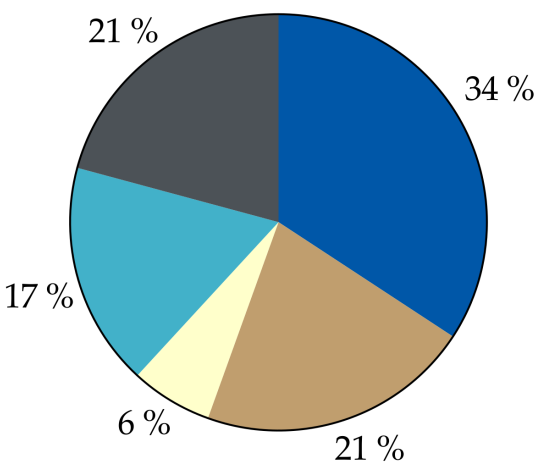

(c)

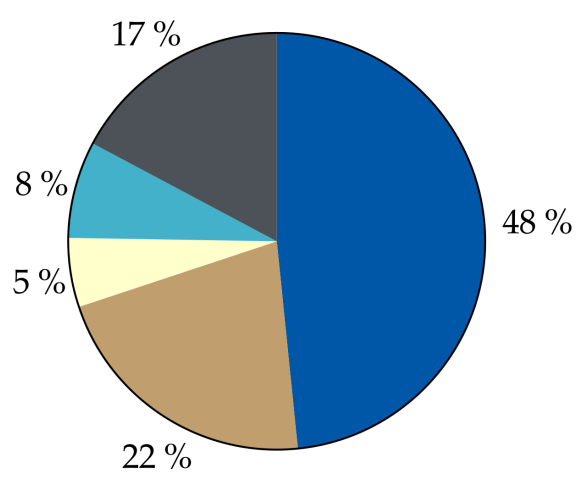

(b)

Total $=93$

Total $=409$

Figure 1. Distribution of HFE genotypes in (a) men, (b) women and (c) the total study population. wt, wildtype.

\subsection{Phenotypic Imprints}

Gender-specific phenotypic imprints are related to ferritin levels in Table 3, and to different HFE genotypes in Table 4 and Figure 2. Except for C282Y heterozygotes, age at referral was significantly lower for men than for women (Figure 2). Furthermore, male C282Y homozygotes were significantly younger than men with other genotypes, while for women this was only the case when compared to C282Y/H63D compound heterozygotes and H63D heterozygotes. There was no significant difference in age when comparing other genotypes, in neither men nor women (Table S1).

Table 3. Median (range) age and biochemical indices at increasing ferritin levels.

\begin{tabular}{ccccccccc}
\hline \multicolumn{7}{c}{ Men } \\
\hline Ferritin $(\mu \mathrm{g} / \mathrm{L})$ & $\boldsymbol{n}$ & $\mathbf{\%}$ & Age $(\mathbf{y r s})$ & $\mathbf{H b}(\mathbf{g} / \mathbf{d L})$ & Tsat $(\%)$ & CRP $(\mathbf{m g} / \mathrm{L})$ & ALAT (U/L) & GGT (U/L) \\
\hline $309-500$ & 42 & 13.3 & $39.4(16.4-70.8)$ & $16.0(14.4-17.3)$ & $43.0(20-80)$ & $1.0(0.2-11)$ & $34.0(11-103)$ & $26.0(9-168)$ \\
$501-700$ & 113 & 35.8 & $47.6(19.4-76.8)$ & $15.8(13.6-18.9)$ & $42.0(11.9-87)$ & $1.0(0.1-12)$ & $34.5(13-148)$ & $30.0(12-214)$ \\
$701-900$ & 74 & 23.4 & $48.8(22.1-74.1)$ & $16.0(14.1-25.7)$ & $42.5(22-89)$ & $1.0(0.4-19)$ & $41.0(14-153)$ & $35.0(16-346)$ \\
$901-1000$ & 32 & 10.1 & $47.0(27.4-73.1)$ & $16.2(13.6-19.1)$ & $48.8(23-93)$ & $2.0(0.9-13)$ & $42.5(16-117)$ & $49.0(11-166)$ \\
$1001-1200$ & 28 & 8.9 & $48.6(31.3-67.6)$ & $16.0(13.6-17.8)$ & $51.0(23-90)$ & $2.0(0.5-11)$ & $44.0(24-243)$ & $38.5(13-233)$ \\
$1201-1500$ & 12 & 3.8 & $57.1(24.5-85.2)$ & $16.3(13.8-17.6)$ & $67.3(31-89)$ & $1.0(0.2-11)$ & $46.0(22-117)$ & $30.0(20-220)$ \\
\hline
\end{tabular}


Table 3. Cont.

\begin{tabular}{|c|c|c|c|c|c|c|c|c|}
\hline \multicolumn{9}{|c|}{ Men } \\
\hline Ferritin $(\mu \mathrm{g} / \mathrm{L})$ & $n$ & $\%$ & Age (yrs) & $\mathrm{Hb}(\mathrm{g} / \mathrm{dL})$ & Tsat (\%) & CRP (mg/L) & ALAT (U/L) & GGT (U/L) \\
\hline $1501-2000$ & 12 & 3.8 & $53.5(36.3-62.5)$ & $16.1(14.4-17.9)$ & $72.4(31.6-84)$ & $1.0(0.5-5)$ & 43.5 (25-179) & 45.0 (15-189) \\
\hline$>2000$ & 3 & 0.9 & $61.6(28.6-65.1)$ & $15.4(14.8-16.8)$ & $59.0(35.5-91)$ & $6.7(3-10.3)$ & $144(83-152)$ & $34.0(20-183)$ \\
\hline \multicolumn{9}{|c|}{ Women } \\
\hline Ferritin $(\mu \mathrm{g} / \mathrm{L})$ & $n$ & $\%$ & Age (yrs) & $\mathrm{Hb}(\mathrm{g} / \mathrm{dL})$ & Tsat (\%) & CRP (mg/L) & ALAT (U/L) & GGT (U/L) \\
\hline $234-500$ & 30 & 32.3 & $52.8(26.8-74.8)$ & $14.8(12.9-16.2)$ & $43.5(24-8$ & $2.0(1-15$ & $26.5(11-38)$ & $24.0(12-75)$ \\
\hline $501-700$ & 32 & 34.4 & $57.3(25.1-79.6)$ & $14.3(12.7-16.3)$ & $48.2(25-82.9)$ & $2.0(0.3-9)$ & $34.0(14-95)$ & $32.5(12-219)$ \\
\hline 701-900 & 20 & 21.5 & $66.3(28.2-79.7)$ & 14.5 (12.9-16.9) & $59.9(32-86.7)$ & $2.0(0.9-10)$ & $29.0(14-104)$ & $23.0(14-91)$ \\
\hline 901-1000 & 5 & 5.4 & $66.1(55.2-72.7)$ & $14.9(13.5-15.7)$ & $43.0(28-78)$ & $5.0(1-6)$ & $40.0(13-41)$ & $30.0(13-327)$ \\
\hline $1001-1200$ & 2 & 2.2 & $63.7(50.5-77.0)$ & $16.0(15.5-16.4)$ & $66.6(49-84.2)$ & $7.6(1.2-14)$ & 94.5 (90-99) & $80.0(70-90)$ \\
\hline $1501-2000$ & 3 & 3.2 & $57.1(54.7-66.2)$ & $14.4(14.1-14.4)$ & $46.7(36-81.0)$ & $4.0(3.6-10.1)$ & $81.0(19-126)$ & $41.0(23-189)$ \\
\hline$>2000$ & 1 & 1.1 & 44.8 & 14.1 & 67.6 & 8.9 & 52.0 & 403 \\
\hline
\end{tabular}

yrs, years; $\mathrm{Hb}$, hemoglobin; Tsat, transferrin saturation; CRP, C-reactive protein; ALAT, alanine aminotransferase; GGT, gammaglutamyl transferase.
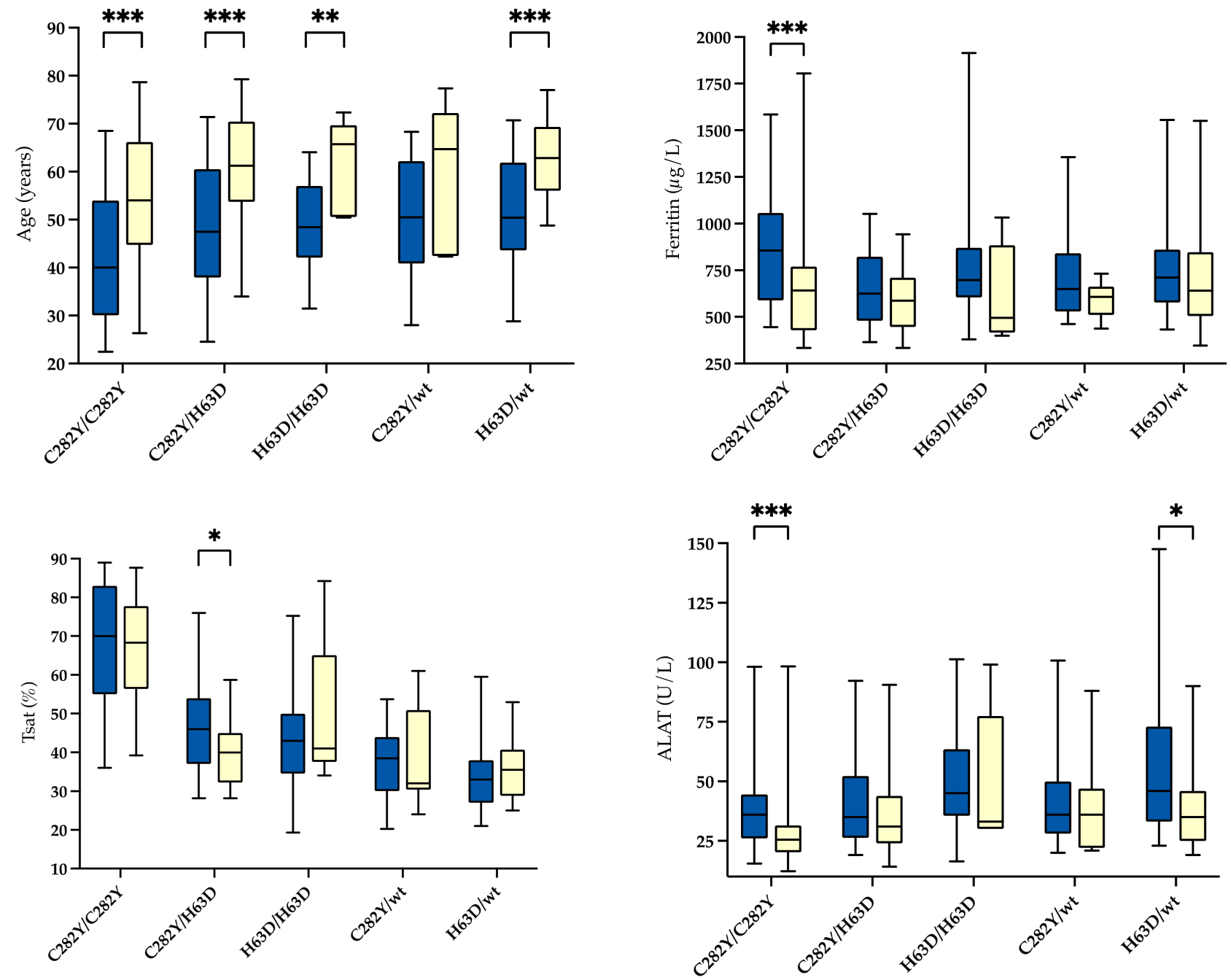

Men $\square$ Women

Figure 2. Genotypic differences in age, ferritin, transferrin saturation (Tsat) and alanine aminotransferase (ALAT) levels by gender. Boxes represent the 25th and 75th percentile and whiskers represent the 5 th and 95th percentile. Significant $p$-values are indicated in figures with asterisks: ${ }^{*} \leq 0.05 ;{ }^{* *} \leq 0.01 ; * * \leq 0.001$. 
Table 4. Age and biochemical findings in relation to genotype.

\begin{tabular}{|c|c|c|c|c|c|c|c|c|c|c|c|c|}
\hline \multirow[b]{2}{*}{ Genotype } & \multirow[b]{2}{*}{$n$} & \multirow{2}{*}{$\begin{array}{c}\text { Age } \\
\begin{array}{c}\text { Median } \\
\text { (yrs) }\end{array}\end{array}$} & \multicolumn{2}{|c|}{ Tsat } & \multicolumn{2}{|c|}{ Ferritin } & \multicolumn{2}{|c|}{ CRP $\mathbb{I I}$} & \multicolumn{2}{|c|}{ ALAT + } & \multicolumn{2}{|c|}{$\mathrm{GGT}^{\S}$} \\
\hline & & & $\begin{array}{c}\text { Median } \\
(\%)\end{array}$ & $\geq 45 \%$ & $\begin{array}{c}\text { Median } \\
(\mu \mathrm{g} / \mathrm{L})\end{array}$ & $\geq 500 \mu \mathrm{g} / \mathrm{L}$ & $\begin{array}{c}\text { Median } \\
(\mathrm{mg} / \mathrm{L})\end{array}$ & $\geq 5 \mathrm{mg} / \mathrm{L}$ & $\begin{array}{c}\text { Median } \\
\text { (U/L) }\end{array}$ & Elevated $^{a}$ & $\begin{array}{c}\text { Median } \\
\text { (U/L) }\end{array}$ & Elevated $^{b}$ \\
\hline \multicolumn{13}{|l|}{ Men } \\
\hline C282Y/C282Y & 95 & 40.0 & 70.0 & $85(89.5 \%)$ & 855 & $87(91.6 \%)$ & 1.0 & $6(6.7 \%)$ & 36.0 & $8(8.6 \%)$ & 27.0 & $3(3.3 \%)$ \\
\hline C282Y/H63D & 67 & 47.5 & 46.0 & $37(55.2 \%)$ & 625 & $47(70.1 \%)$ & 1.4 & $14(21.5 \%)$ & 35.0 & $6(9.4 \%)$ & 38.0 & $5(7.8 \%)$ \\
\hline H63D/H63D & 21 & 48.4 & 43.0 & $7(33.3 \%)$ & 698 & $20(95.2 \%)$ & 1.0 & $2(9.5 \%)$ & 45.0 & $3(14.3 \%)$ & 33.0 & $1(4.8 \%)$ \\
\hline $\mathrm{H} 63 \mathrm{D} / \mathrm{wt}$ & 69 & 52.8 & 33.0 & $12(17.4 \%)$ & 711 & $63(91.3 \%)$ & 1.7 & $2(2.9 \%)$ & 46.0 & $18(26.1 \%)$ & 48.0 & $8(11.6 \%)$ \\
\hline Total & 316 & 47.4 & 44.1 & $156(49.4 \%)$ & 712 & $274(86.7 \%)$ & 1.0 & 31 (10.1\%) & 39.0 & $41(13.2 \%)$ & 34.0 & $20(6.8 \%)$ \\
\hline \multicolumn{13}{|l|}{ Women } \\
\hline C282Y/C282Y & 44 & 54.0 & 68.3 & $39(88.6 \%)$ & 641 & $30(68.2 \%)$ & 2.0 & $8(18.2 \%)$ & 25.5 & $4(9.1 \%)$ & 21.0 & $3(6.8 \%)$ \\
\hline C282Y/H63D & 21 & 61.3 & 40.0 & $5(23.8 \%)$ & 587 & $13(61.9 \%)$ & 2.0 & $4(20 \%)$ & 31.0 & $5(23.8 \%)$ & 28.0 & $3(14.3 \%)$ \\
\hline H63D/H63D & 5 & 65.7 & 41.0 & $2(40.0 \%)$ & 495 & $2(40.0 \%)$ & 1.1 & $1(25 \%)$ & 33.0 & $2(40.0 \%)$ & 34.0 & $0(0.0 \%)$ \\
\hline $\mathrm{H} 63 \mathrm{D} / \mathrm{wt}$ & 16 & 62.8 & 35.5 & $3(18.8 \%)$ & 640 & $12(75.0 \%)$ & 2.5 & $5(31.3 \%)$ & 35.0 & $4(25.0 \%)$ & 34.5 & $4(25 \%)$ \\
\hline Total & 93 & 57.9 & 46.7 & $51(54.8 \%)$ & 631 & $63(67.7 \%)$ & 2.0 & $20(22.0 \%)$ & 29.0 & $17(18.3 \%)$ & 27.0 & $10(10.8 \%)$ \\
\hline
\end{tabular}

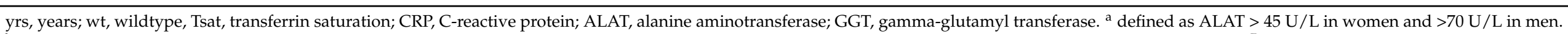

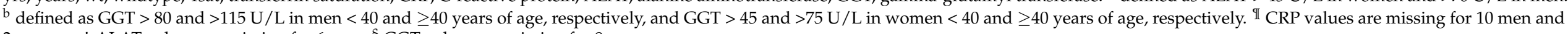

2 women. + ALAT values are missing for 6 men. ${ }^{\S}$ GGT values are missing for 9 men. 
All subjects had ferritin $\geq 300 \mu \mathrm{g} / \mathrm{L}$ (i.e., above upper reference value for men) except a female 26-year-old C282Y homozygote with ferritin levels of $234 \mu \mathrm{g} / \mathrm{L}$. Median ferritin was significantly higher in men than women $(p \leq 0.001)$, although the highest value of $4645 \mu \mathrm{g} / \mathrm{L}$ was found in 45-year-old women. Among men, the highest ferritin value was observed in a 62-year-old exhibiting a ferritin level of $2536 \mu \mathrm{g} / \mathrm{L}$ (Table 3).

Of men, $59.2 \%$ had ferritin $501-900 \mu \mathrm{g} / \mathrm{L}$, and $27.5 \% \geq 900 \mu \mathrm{g} / \mathrm{L}$. Corresponding levels for women were $55.9 \%$ and $11.9 \%$. At all ferritin levels between $300-2000 \mu \mathrm{g} / \mathrm{L}$, median age was higher among women than men, irrespective of HFE genotype (Table 3). Furthermore, in men median age was kept stable, just below 50 years at increasing ferritin levels from 501 to $1200 \mu \mathrm{g} / \mathrm{L}$, and in women around 66 years with ferritin between 701 and $1200 \mu \mathrm{g} / \mathrm{L}$.

Up to ferritin $900 \mu \mathrm{g} / \mathrm{L}$, male median Tsat was rather stable, around $42-43 \%$, whereafter it increased linearly to $72.4 \%$ as ferritin stepwise increased towards $2000 \mu \mathrm{g} / \mathrm{L}$. Similarly, apart from an unexplainable drop in the median of five individuals, median Tsat in women was practically linear from $43.5 \%$ to $66.6 \%$ at ferritin levels up to $1200 \mu \mathrm{g} / \mathrm{L}$.

In men, there was no real change in median ALAT, which was kept around 41-46 U/L, well below the upper reference limit of $70 \mathrm{U} / \mathrm{L}$, at any ferritin level up to $2000 \mu \mathrm{g} / \mathrm{L}$. A similar trend was seen in women up to a ferritin level of $900 \mu \mathrm{g} / \mathrm{L}$. Above this level, ALAT was markedly increased in single subjects.

C282Y homozygous men and women showed the highest median ferritin of 855 and $641 \mu \mathrm{g} / \mathrm{L}$, with $91.6 \%$ and $68.2 \%$ of the values being $\geq 500 \mu \mathrm{g} / \mathrm{L}$, respectively (Table 4 ). In men with other genotypes, median ferritin varied between 625 and $711 \mu \mathrm{g} / \mathrm{L}$, with genotypic proportions of ferritin $\geq 500 \mu \mathrm{g} / \mathrm{L}$ ranging from $70.1 \%$ to $95.2 \%$. In total, $86.7 \%$ of male subjects had ferritin $\geq 500 \mu \mathrm{g} / \mathrm{L}$. The corresponding findings in female non-C282Y homozygotes were median ferritin between 495 and $640 \mu \mathrm{g} / \mathrm{L}$, and genotypic proportions with ferritin $\geq 500 \mu \mathrm{g} / \mathrm{L}$ ranging from $40.0 \%$ to $85.7 \%$. A total of $67.7 \%$ of the female study population had ferritin $\geq 500 \mu \mathrm{g} / \mathrm{L}$.

Except for C282Y homozygotes, where median ferritin was significantly higher in men than women $(p \leq 0.001)$, there was no significant gender difference in ferritin levels in relation to genotypes (Figure 2).

Median Tsat was a slightly, although insignificantly, higher among women than men $(46.7 \%$ vs. $44.1 \%)$. When evaluating separate HFE genotypes, male Tsat tended to surpass that of the female group with a weak statistical significance only for C282Y/H63D compound heterozygotes (Figure 2). Median Tsat above the threshold, defined as the upper male reference level of $45.0 \%$, was, with one negligible exception in male C282Y/H63D compound heterozygotes, only found in C282Y homozygotes with a median of $70.0 \%$ in men and $68.3 \%$ in women (Table 4 ). In total, $89.5 \%$ of these men and $88.6 \%$ of these women had Tsat $\geq 45 \%$. The median Tsat of the male group was $44.1 \%$ with $49.4 \%$ above the threshold, and in women the corresponding values were $46.7 \%$ and $54.8 \%$, respectively (Table 4). In men, C282Y homozygotes showed a significantly higher median Tsat compared to all genotypes (Table 4, Table S1). This was also the case in C282Y homozygote women (median 68.3\%), except for H63D homozygotes (median $41 \%)(p=0.051)$, which only accounted for five subjects in total.

On a group level, median ALAT and GGT levels were significantly higher in men than women, although they were well within the reference range for both genders (Table 1). When related to genotype, however, significant gender differences in ALAT were limited to C282Y homozygotes and H63D heterozygotes (Figure 2). Proportion of subjects with elevated ALAT and GGT levels were too small make inferences about specific genotype associations within the groups (Table 4 ). As a whole, $13.2 \%$ of the men had ALAT $>70 \mathrm{U} / \mathrm{L}$ and $6.8 \%$ had GGT levels above the gender- and age-specific reference intervals. The corresponding results in women were elevated ALAT and GGT in $18.3 \%$ and $10.8 \%$ of subjects, respectively. Additionally, there was a weak positive correlation between ferritin and ALAT in both genders: in men, $r=0.291(p \leq 0.001)$, and in women, $r=0.309(p \leq 0.01)$ (Table S2). 


\subsection{Ferritin $\geq 1000 \mu \mathrm{g} / \mathrm{L}$ and Elevated Transferrin Saturation}

We defined Tsat levels $\geq 70 \%$ as significantly elevated. A total of 53 men $(16.8 \%)$ and $22(23.7 \%)$ women exhibited such levels, two of which were H63D homozygotes, and the rest being either $\mathrm{C} 282 \mathrm{Y}$ homozygous $(n=69)$ or $\mathrm{C} 282 \mathrm{Y} / \mathrm{H} 63 \mathrm{D}$ compound heterozygous $(n=4)$. Likewise, a pathological ferritin $\geq 1000 \mu \mathrm{g} / \mathrm{L}$ was found in a total of 61 subjects (14.9\% of total population), which included $17.4 \%$ of the male population $(n=55)$ and $6.5 \%$ of the female population $(n=6)$ (Table 5). The majority of these men $(52.7 \%)$ and half of these women were $\mathrm{C} 282 \mathrm{Y}$ homozygotes.

Table 5. Proportion with significantly elevated ferritin and transferrin saturation (Tsat) at referral.

\begin{tabular}{|c|c|c|c|c|c|c|}
\hline \multirow{2}{*}{ Genotype } & & \multirow{2}{*}{ Tsat $\underset{n}{\geq}$} & \multirow{2}{*}{$\begin{array}{c}\text { Ferritin } \\
\geq n\end{array}$} & \multicolumn{3}{|c|}{ Combined Ferritin $\geq 1000 \mu \mathrm{g} / \mathrm{L}$ and Tsat $\geq 45 \%$} \\
\hline & & & & $n$ & Age (years) & $\%$ of Total \\
\hline \multirow{2}{*}{ C282Y/C282Y } & Men & 48 & 29 & 26 & $28.6-73.2^{\dagger}$ & 27.4 \\
\hline & Women & 21 & 3 & 3 & $44.8,54.7,66.2$ & 6.8 \\
\hline \multirow{2}{*}{ C282Y/H63D } & Men & 4 & 5 & 3 & $24.5,59.6,85.1$ & 4.5 \\
\hline & Women & 0 & 0 & 0 & - & 0 \\
\hline \multirow{2}{*}{ H63D/H63D } & Men & 1 & 2 & 1 & 55.6 & 4.8 \\
\hline & Women & 1 & 1 & 1 & 50.5 & 20 \\
\hline \multirow{2}{*}{$\mathrm{C} 282 \mathrm{Y} / \mathrm{wt}$} & Men & 0 & 9 & 3 & $33.4,54.2,62.5$ & 4.7 \\
\hline & Women & 0 & 0 & 0 & - & 0 \\
\hline \multirow{2}{*}{$\mathrm{H} 63 \mathrm{D} / \mathrm{wt}$} & Men & 0 & 10 & 3 & $48.0,59.1,61.6$ & 4.3 \\
\hline & Women & 0 & 2 & 1 & 77.0 & 6.3 \\
\hline \multirow{2}{*}{ Total } & Men & 53 & 55 & 36 & $24.5-85.2^{\dagger}$ & 11.4 \\
\hline & Women & 22 & 6 & 5 & $44.8-77.0^{\dagger}$ & 5.4 \\
\hline
\end{tabular}

$w t$, wildtype; Tsat, transferrin saturation. Genotypic population who displayed such characteristics. $\uparrow$, range.

In women with ferritin $\geq 1000 \mu \mathrm{g} / \mathrm{L}$, median CRP, ALAT and GGT were significantly higher compared to women with ferritin $<1000 \mu \mathrm{g} / \mathrm{L}$. Among men, a similar difference was only seen for ALAT (Figure 3).
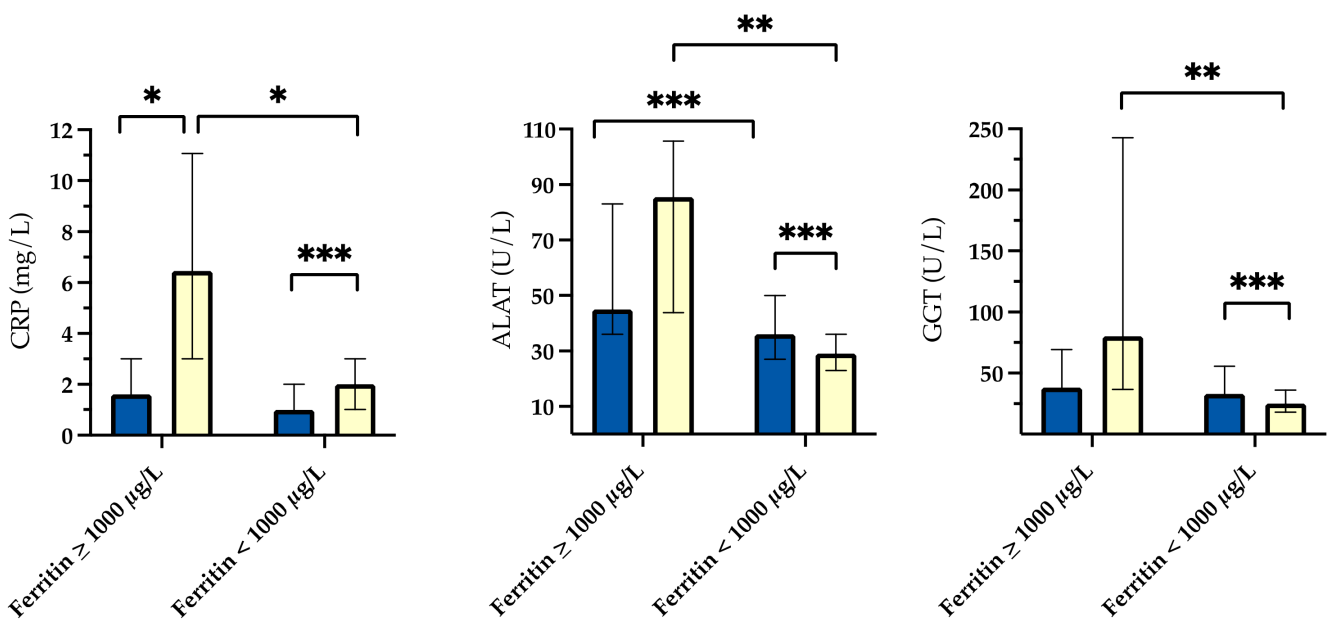

$\square$ Men

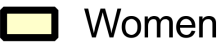

Figure 3. Median C-reactive protein (CRP), alanine aminotransferase (ALAT) and gamma-glutamyl transferase (GGT) in subjects with and without significantly elevated ferritin. Bars represent interquartile range. Significant $p$-values are indicated in figures with asterisks: ${ }^{*} \leq 0.05 ;{ }^{* *} \leq 0.01$; $* * * 0.001$.

A total of $11.4 \%(n=36)$ of the total male population and $5.4 \%(n=5)$ of the total female population presented with a combined ferritin $\geq 1000 \mu \mathrm{g} / \mathrm{L}$ and Tsat $\geq 45 \%$. Of 
these subjects, 70\% (26 men, 3 women) were C282Y homozygotes (Table 5). There was no significant correlation between ferritin and age, CRP, Tsat, ALAT or GGT levels for these subjects.

\subsection{CRP and Ferritin Correlation}

A significant difference in CRP levels between men and women was detected (Table 1), although median levels were 1.0 and $2.0 \mathrm{mg} / \mathrm{L}$, respectively, and well below the upper reference limit of $5 \mathrm{mg} / \mathrm{L}$. Nevertheless, $10 \%$ of men and $22 \%$ of women had increased CRP of up to 15-19 mg/L, which indicated inflammation with a potential confounding effect that could contribute to the observed hyperferritinemia. There was in fact a weak positive correlation between CRP and ferritin levels in men $(r=0.205, p \leq 0.001)$ and women $(r=0.236, p \leq 0.05)$ (Table S2). There was, however, no significant difference in ferritin levels when comparing subjects with and without abnormal CRP, neither in men $(p=0.081)$, nor in women $(p=0.293)$. The ferritin-CRP correlation was strongest in C282Y heterozygous men $(r=0.399, p \leq 0.01)$ and in H63D heterozygous women $(r=0.545$, $p \leq 0.05)$.

\section{Discussion}

In this observational study, we describe the association between biochemical findings, age, gender and HFE genotype in patients referred from general practice to a tertiary care referral center for diagnostic workup on the basis of persistent hyperferritinemia and suspected hereditary hemochromatosis. Only patients with HFE variants were included (Figure 1). Comorbidities contributing to a reactive hyperferritinemia were thoroughly investigated, but could not be completely ruled out. Thus, even if the median CRP was normal, some patients had a small increase, and a weak positive correlation between CRP and ferritin levels was detected (Table S2). A low-grade subclinical inflammation could therefore not be completely excluded, however, with a negligible impact, if any at all.

For example, non-alcoholic fatty liver disease may contribute to reactive, inflammatory hyperferritinemia, and it may also contribute to hepatic iron overload itself through what is referred to as dysmetabolic iron overload syndrome [15]. The wide dispersion of ALAT and GGT values as shown in Table 3 might indicate such an association. While some patients were referred to hepatic magnetic resonance imaging or liver elastography to evaluate the iron burden of the liver, this was not routine practice.

In the preclinical stage, when a convincing correlation between elevated Tsat and ferritin may be absent, the initial diagnostic workup of suspected hemochromatosis often proves to be difficult, not least because hyperferritinemia is a non-specific marker of pathological iron overload [16]. With Tsat being an important marker for genetic penetrance in HFE hemochromatosis and a measure of iron accumulation rate, our results confirm C282Y homozygosity as a superior cause of abnormally increased iron accumulation at the population level of this specific area. This complies with the current opinion that the genetic strength required to generate a sizable iron overload, which is big enough to cause clinical disease, is largely restricted to C282Y homozygosity [2,17]. This is valid for both genders; however, women are hit several years after men (Figure 2).

Of all subjects, $85 \%$ did not comply with the most important hallmark for complete penetrance of HFE hemochromatosis, which is Tsat within the range of $70-100 \%$ [18]. However, when evaluating separate genotypes, a convincing hemochromatotic biochemical pattern emerged in C282Y homozygote men with a median ferritin which was significantly higher compared to the other HFE genotypes (Table 4, Table S1), except H63D homozygotes. While median Tsat in C282Y homozygote women equaled that in men, ferritin was not significantly increased beyond that of non-C282Y homozygotes, with a median around $600 \mu \mathrm{g} / \mathrm{L}$ (Table 4, Table S1).

Not more than $27 \%$ of C282Y homozygote men and $7 \%$ of women (at postmenopausal age) had a serious risk profile for developing liver complications, which is generally acknowledged as Tsat $\geq 45 \%$ and ferritin $>1000 \mu \mathrm{g} / \mathrm{L}$ (Table 5) [19-21]. Even though this 
finding is in line with the fact that $\mathrm{C} 282 \mathrm{Y}$ homozygotes are not obligatorily exposed to the development of a dangerous iron overload, one must realize that they were relatively young with a median age of 40 years, and many would therefore be at increasing risk in the years to come. A similar risk profile was found in ten men and two women with other HFE genotypes.

An early sign of damage is leakage of ALAT from affected liver cells [13,22]. In accordance with this, serum concentration of ALAT was significantly higher in patients with ferritin $\geq 1000 \mu \mathrm{g} / \mathrm{L}$ compared to those with levels $<1000 \mu \mathrm{g} / \mathrm{L}$, although median ALAT did not surpass the upper reference limit, in contrast to women, who showed a moderate increase (Figure 3).

As shown in Figure 2, the non-C282Y homozygotes displayed mild to moderate hyperferritinemia, up to $500-700 \mu \mathrm{g} / \mathrm{L}$, which may be explained by increased iron storage, but external or environmental impact, and not to mention more rare genetic conditions, may also be causative. However, median Tsat in different genotypes was $32-46 \%$ and a consistent Tsat of above $26 \%$ and $23 \%$ was found in HFE wildtype men and women, respectively, in a Norwegian hemochromatosis screening which comprised around 65,000 volunteers [23]. In addition, it should be noted that $32 \%$ of the men and $24 \%$ of the women had Tsat $>45 \%$ (Table 3). Confounding effects due to extreme iron supplementation or regular intake of iron-rich food, such as red meat, was not a reality in our study population.

Nevertheless, we have shown that there was a minimal difference between Tsat in the various non-C282Y homozygote genotypes, the maximum being $9 \%$ in women and $13 \%$ in men. This was also indirectly suggested by the corresponding small difference between the highest and lowest median ferritin values, which was not more than $86 \mu \mathrm{g} / \mathrm{L}$ in men and $145 \mu \mathrm{g} / \mathrm{L}$ in women. The slight variation in iron overload can be attributed to individual factors such as age, lifestyle and environmental impact.

Historically, non-C282Y homozygote subjects with a stable, mild to moderate iron overload with hyperferritinemia $<1000 \mu \mathrm{g} / \mathrm{L}$ have been considered to be at low risk of serious disease [24]. However, the issue is controversial and has been revitalized in light of recently growing evidence that superfluous iron certainly may aggravate the pathogenesis of other, contemporary diseases such as inflammation, cancer, alcoholism and hepatopathy [25-30]. This possibility should not be neglected by clinicians.

Notwithstanding that superfluous iron is preferably deposited in the liver parenchyma, other parenchymatous tissues may be targeted as well, and malfunction might be expressed as (mild) diffuse clinical symptoms or an increase in disease-specific symptoms. Even if this is difficult to prove, the potential pathogenetic impact of iron has gained substantial interest and has been suggested in a wide spectrum of diseases other than liver disease. Of particular interest, is the hypothetical role of iron in degenerative neurological diseases, such as Alzheimer's and Parkinson's disease [31,32].

As a whole, the hemochromatotic phenotype indeed depends on the susceptibility of the molecular changes induced by the genetic variants to "external" factors, not to mention other rare variants of which an unknown number awaits discovery. To translate the described associations of this study into rationalized, individual patient care is indeed challenged by the great range and variation in Tsat and ferritin levels in all HFE genotypes (Figure 2). Extreme individual Tsat, combined with the highly elevated ferritin values detected in non-C282Y homozygotes (Table 5), may be a consequence of such hitherto unknown confounding factors. Novel genetic variants and digenic models of inheritance have been identified [33-35], although much is still unknown regarding environmental and genetic cofactors contributing to iron overload. The modifying effects of epigenetics, miRNA and other gene-regulating mechanisms may also help explain the rather substantially variable phenotype which at present is observed, but only partly understood.

\section{Conclusions}

The considerable variation in Tsat and ferritin, independent of HFE genotype, may indeed represent a diagnostic challenge in general practice. This is in particular true for ferritin, 
which on a regular basis is the diagnostic entrance to abnormal iron metabolism and suspicion of hemochromatosis. On the other hand, permanently increased Tsat $>45 \%$ is a rather specific marker for increased iron absorption and genetic penetrance in HFE hemochromatosis.

Supplementary Materials: The following are available online at https:/ /www.mdpi.com/article/10 .3390/genes12081162/s1, Table S1: Genotypic differences in age and iron status, Table S2: Correlation between ferritin, age and biochemical parameters.

Author Contributions: Conceptualization, M.V., R.J.U. and H.R.; methodology, H.R.; investigation, M.S., M.V., R.J.U. and H.R.; formal analysis, M.S. and H.R.; writing—original draft preparation, M.S.; writing - review and editing, M.S., M.V., R.J.U. and H.R.; visualization, M.S.; supervision, M.V. and H.R. All authors have read and agreed to the published version of the manuscript.

Funding: The study did not receive any specific grant from funding agencies in the public, commercial or not-for-profit sectors.

Institutional Review Board Statement: The regional Ethics Committee (REK) classified the study as quality assurance; thus, we did not need ethical assessment and informed consent. The hospital data protection officer approved the study. The study was conducted in accordance with the Code of Ethics of the World Medical Association (Declaration of Helsinki) and the study protocol was approved by the Norwegian Centre for Research Data (protocol $N^{\circ} 58828$ ).

Informed Consent Statement: The Regional Ethics Committee classified the study as quality assurance, without need for individual informed consent. The hospital data protection officer approved the study.

Acknowledgments: The Medical Student Research Program at the Faculty of Medicine, University of Bergen, headed by Anne Berit Guttormsen is acknowledged for encouraging and supporting this work.

Conflicts of Interest: The authors declare no conflict of interest.

\section{References}

1. Feder, J.; Gnirke, A.; Thomas, W.; Tsuchihashi, Z.; Ruddy, D.; Basava, A.; Dormishian, F.; Domingo, R.; Ellis, M.; Fullan, A.; et al. A novel MHC class I-like gene is mutated in patients with hereditary haemochromatosis. Nat. Genet. 1996, 13, 399-408. [CrossRef]

2. Merryweather-Clarke, A.T.; Pointon, J.J.; Shearman, J.D.; Robson, K.J. Global prevalence of putative haemochromatosis mutations. J. Med. Genet. 1997, 34, 275-278. [CrossRef] [PubMed]

3. Bacon, B.R.; Powell, L.W.; Adams, P.C.; Kresina, T.F.; Hoofnagle, J.H. Molecular medicine and hemochromatosis: At the crossroads. Gastroenterology 1999, 116, 193-207. [CrossRef]

4. Hanson, E.H.; Imperatore, G.; Burke, W. HFE gene and hereditary hemochromatosis: A HuGE review. Human Genome Epidemiology. Am. J. Epidemiol. 2001, 154, 193-206. [CrossRef]

5. Allen, K.J.; Gurrin, L.C.; Constantine, C.C.; Osborne, N.J.; Delatycki, M.B.; Nicoll, A.J.; McLaren, C.E.; Bahlo, M.; Nisselle, A.E.; Vulpe, C.D.; et al. Iron-overload-related disease in HFE hereditary hemochromatosis. N. Engl. J. Med. 2008, 358, 221-230. [CrossRef]

6. Beutler, E.; Felitti, V.J.; Koziol, J.A.; Ho, N.J.; Gelbart, T. Penetrance of 845G $\rightarrow$ A (C282Y) HFE hereditary haemochromatosis mutation in the USA. Lancet 2002, 359, 211-218. [CrossRef]

7. Åsberg, A.; Hveem, K.; Thorstensen, K.; Ellekjaer, E.; Kannelønning, K.; Fjøsne, U.; Halvorsen, T.B.; Smethurst, H.B.; Sagen, E.; Bjerve, K.S. Screening for hemochromatosis: High prevalence and low morbidity in an unselected population of 65,238 persons. Scand. J. Gastroenterol. 2001, 36, 1108-1115.

8. Alexander, J.; Kowdley, K.V. HFE-associated hereditary hemochromatosis. Genet. Med. 2009, 11, 307-313. [CrossRef] [PubMed]

9. Adams, P.C.; Barton, J.C. Haemochromatosis. Lancet 2007, 370, 1855-1860. [CrossRef]

10. Adams, P.C.; Reboussin, D.M.; Barton, J.; McLaren, C.E.; Eckfeldt, J.H.; McLaren, G.D.; Dawkins, F.W.; Acton, R.T.; Harris, E.L.; Gordeuk, V.R.; et al. Hemochromatosis and iron-overload screening in a racially diverse population. N. Engl. J. Med. 2005, 352, 1769-1778. [CrossRef]

11. Wang, W.; Knovich, M.A.; Coffman, L.G.; Torti, F.M.; Torti, S.V. Serum ferritin: Past, present and future. Biochim. Biophys. Acta 2010, 1800, 760-769. [CrossRef] [PubMed]

12. Gurrin, L.; Osborne, N.; Constantine, C.C.; McLaren, C.E.; English, D.; Gertig, D.M.; Delatycki, M.B.; Southey, M.C.; Hopper, J.L.; Giles, G.; et al. The natural history of serum iron indices for HFE C282Y homozygosity associated with hereditary hemochromatosis. Gastroenterology 2008, 135, 1945-1952. [CrossRef] 
13. Bacon, B.R.; Adams, P.C.; Kowdley, K.V.; Powell, L.W.; Tavill, A.S.; American Association for the Study of Liver Diseases. Diagnosis and management of hemochromatosis: 2011 practice guideline by the American Association for the Study of Liver Diseases. Hepatology 2011, 54, 328-343. [CrossRef]

14. McLaren, C.E.; McLachlan, G.; Halliday, J.W.; Webb, S.I.; Leggett, B.; Jazwinska, E.C.; Crawford, D.H.; Gordeuk, V.R.; McLaren, G.D.; Powell, L.W. Distribution of transferrin saturation in an Australian population: Relevance to the early diagnosis of hemochromatosis. Gastroenterology 1998, 114, 543-549. [CrossRef]

15. Dongiovanni, P.; Fracanzani, A.L.; Fargion, S.; Valenti, L. Iron in fatty liver and in the metabolic syndrome: A promising therapeutic target. J. Hepatol. 2011, 55, 920-932. [CrossRef] [PubMed]

16. Sandnes, M.; Ulvik, R.J.; Vorland, M.; Reikvam, H. Hyperferritinemia-A Clinical Overview. J. Clin. Med. 2021, 10, 2008. [CrossRef] [PubMed]

17. Grosse, S.D.; Gurrin, L.C.; Bertalli, N.A.; Allen, K.J. Clinical penetrance in hereditary hemochromatosis: Estimates of the cumulative incidence of severe liver disease among HFE C282Y homozygotes. Genet. Med. 2018, 20, 383-389. [CrossRef]

18. Edwards, C.Q.; Kushner, J.P. Screening for hemochromatosis. N. Engl. J. Med. 1993, 328, 1616-1620.

19. Beaton, M.; Guyader, D.; Deugnier, Y.; Moirand, R.; Chakrabarti, S.; Adams, P. Noninvasive prediction of cirrhosis in C282Y-linked hemochromatosis. Hepatology 2002, 36, 673-678. [CrossRef]

20. Waalen, J.; Felitti, V.J.; Gelbart, T.; Beutler, E. Screening for hemochromatosis by measuring ferritin levels: A more effective approach. Blood 2008, 111, 3373-3376. [CrossRef]

21. Kowdley, K.V.; Brown, K.E.; Ahn, J.; Sundaram, V. ACG Clinical Guideline: Hereditary Hemochromatosis. Am. J. Gastroenterol. 2019, 114, 1202-1218. [CrossRef]

22. European Association For The Study Of The Liver. EASL clinical practice guidelines for HFE hemochromatosis. J. Hepatol. 2010, 53, 3-22. [CrossRef] [PubMed]

23. Thorstensen, K.; Kvitland, M.A.; Irgens, W.O.; Hveem, K.; Asberg, A. Screening for C282Y homozygosity in a Norwegian population (HUNT2): The sensitivity and specificity of transferrin saturation. Scand. J. Clin. Lab. Investig. 2010, 70, 92-97. [CrossRef] [PubMed]

24. Edwards, C.Q.; Griffen, L.M.; Bulaj, Z.J.; Ajioka, R.S.; Kushner, J.P. The iron phenotype of hemochromatosis heterozygotes. In Hemochromatosis: Genetics, Pathophysiology, Diagnosis and Treatment; Barton, J.C., Edwards, C.Q., Eds.; Cambridge University Press: Cambridge, UK, 2000; pp. 411-418.

25. Torti, S.V.; Torti, F.M. Iron and cancer: More ore to be mined. Nat. Rev. Cancer 2013, 13, 342-355. [CrossRef] [PubMed]

26. Wessling-Resnick, M. Iron homeostasis and the inflammatory response. Annu. Rev. Nutr. 2010, 30, 105-122. [CrossRef]

27. Franchini, M.; Targher, G.; Capra, F.; Montagnana, M.; Lippi, G. The effect of iron depletion on chronic hepatitis C virus infection. Hepatol. Int. 2008, 2, 335-340. [CrossRef] [PubMed]

28. Perricone, C.; Bartoloni, E.; Bursi, R.; Cafaro, G.; Guidelli, G.M.; Shoenfeld, Y.; Gerli, R. COVID-19 as part of the hyperferritinemic syndromes: The role of iron depletion therapy. Immunol. Res. 2020, 68, 213-224. [CrossRef] [PubMed]

29. Milic, S.; Mikolasevic, I.; Orlic, L.; Devcic, E.; Čizmarević, N.S.; Stimac, D.; Kapovic, M.; Ristić, S. The Role of Iron and Iron Overload in Chronic Liver Disease. Med. Sci. Monit. 2016, 22, 2144-2151. [CrossRef]

30. Harrison-Findik, D.D. Role of alcohol in the regulation of iron metabolism. World J. Gastroenterol. 2007, 13, 4925-4930. [CrossRef]

31. Ward, R.J.; Zucca, F.A.; Duyn, J.H.; Crichton, R.R.; Zecca, L. The role of iron in brain ageing and neurodegenerative disorders. Lancet Neurol. 2014, 13, 1045-1060. [CrossRef]

32. Zecca, L.; Youdim, M.B.; Riederer, P.; Connor, J.R.; Crichton, R.R. Iron, brain ageing and neurodegenerative disorders. Nat. Rev. Neurosci. 2004, 5, 863-873. [CrossRef] [PubMed]

33. Jacolot, S.; Le Gac, G.; Scotet, V.; Quere, I.; Mura, C.; Ferec, C. HAMP as a modifier gene that increases the phenotypic expression of the HFE pC282Y homozygous genotype. Blood 2004, 103, 2835-2840. [CrossRef] [PubMed]

34. Merryweather-Clarke, A.T.; Cadet, E.; Bomford, A.; Capron, D.; Viprakasit, V.; Miller, A.; McHugh, P.J.; Chapman, R.W.; Pointon, J.J.; Wimhurst, V.L.; et al. Digenic inheritance of mutations in HAMP and HFE results in different types of haemochromatosis. Hum. Mol. Genet. 2003, 12, 2241-2247. [CrossRef]

35. Bomford, A. Genetics of haemochromatosis. Lancet 2002, 360, 1673-1681. [CrossRef] 